\title{
STANDARDIZATION AND PHYTOCHEMICAL SCREENING OF BOUGAINVILLEA GLABRA
}

\author{
RAKAM GOPI KRISHNA', RAJA S. ${ }^{2 *}$
}

1Department of Pharmaceutical Chemistry, Chaitanya College of Pharmacy Education and Research, Kishanpura, Hanamkonda, Warangal, Telangana, India 506001, 2Gitam Institute of Pharmacy, Gitam University, Visakhapatnam Andhra Pradesh

Email: sraja61@gmail.com

Received: 23 May 2017, Revised and Accepted: 22 Jul 2017

\section{ABSTRACT}

Objective: The objective of the current study was to identify, authenticate and prevent the adulteration of the plant Bougainvillea glabra. The following physicochemical parameters such as standardization, extraction and preliminary phytochemical screening helped in correct identification of the plant Bougainvillea glabra.

Methods: Standardization includes the estimation of physicochemical parameters such as loss on drying, determination of $\mathrm{pH}$ range, determination of total ash, determination of water soluble ash, determination of acid insoluble ash, determination of sulfated ash and determination of hot water and ethanol-extractable matter. Preliminary phytochemical screening and TLC studies for all the extracts like chloroform, ethyl acetate and methanol were carried out by standard methods.

Results: Results of loss on drying and the total ash value were found to be $8.1+0.24$ and $6.26 \pm 0.05$ respectively. The result for water soluble ash was found to be $1.34+0.04$. The results for acid insoluble ash and sulfated ash were found to be $1.35 \pm 0.03$ and $1.10 \pm 0.07$, respectively. The values for water soluble and ethanol soluble extractive parameters were found to be $23.45 \pm 1.13$ and $12.32 \pm 0.41$ respectively Preliminary phytochemical screening for all the extracts revealed the presence of alkaloids, flavonoids, terpenoids, -glycosides and steroids in Bougainvillea glabra. Major constituents like alkaloids, flavonoids, tannins and glycosides were present in methanol extract. Alkaloids and flavonoids were also found in chloroform extract. The thin layer chromatography analysis of Bougainvillea glabra chloroform extract showed the presence of steroids with $\mathrm{R}_{\mathrm{f}}$ values of 0.66 and 0.34 in benzene: ethyl acetate (85:15), chloroform: methanol (8:2) solvent systems correspondingly. The TLC analysis of ethyl acetate extract showed the presence of flavonoids with $\mathrm{R}_{\mathrm{f}}$ values of 0.66 and 0.75 in toluene: dioxin: acetic acid (78:14:5) chloroform: acetone: formic acid (64:12.3:3.2) solvent systems, correspondingly.

Conclusion: The results of standardization parameters ensure quality and purity of the plant material Bougainvillea glabra. Phytochemical screening revealed the presence of various phytoconstituents like flavonoids, alkaloids and glycosides. TLC studies indicated the ash value, $\mathrm{pH}$ determination and solubility parameters. The data obtained from the present study provide useful data which will helpful in identification and doing research work in future.

Keywords: Bougainvillea glabra, Extraction, Solvents, TLC analysis and phytochemical screening

(C) 2017 The Authors. Published by Innovare Academic Sciences Pvt Ltd. This is an open access article under the CC BY license (http://creativecommons.org/licenses/by/4.0/]

DOI: http://dx.doi.org/10.22159/ijcpr.2017v9i5.22143

\section{INTRODUCTION}

As commercialization of the herbal medicine has happened, assurance of safety, quality and efficacy of medicinal plants and herbal products has become an important issue. The herbal raw material is liable to a lot of dissimilarities due to several factors, the essential ones being the identity of the plants and seasonal variation (which has a bearing on the time of collection), the ecotypic, genotypic and chemotypic variations, drying and storage conditions and the presence of xenobiotic [1]. Standardization of drugs means confirmation of its identity and determination of its quality and purity. Standardization is a crucial measurement for certifying the quality control of the herbal drugs. Standardization of herbal raw drugs includes passport data of raw plant drugs, botanical authentification, microscopic and molecular examination, identification of chemical composition by various chromatographic techniques and biological activity of the whole plant [2]. Ethnomedical information shows that Bougainvillea glabra is used in many parts of the world for the treatment of several diseases like helminthiasis [3], diabetes [4], respiratory illness, cough, cold and bronchitis [5], ulcers and diarrhoea. Bougainvillea glabra possess various pharmacological activities like analgesic, antipyretic and anti-inflammatory activities [6]. The plants possess antibacterial activity against gram positive bacteria, Bacillus subtilis and gram negative bacteria, Escherichia coli [7]. Aqueous extract of the leaves of Bougainvillea glabra possesses antidiabetic and antilipidemic effects [8]. Bougainvillea glabra possess steroidal compounds with anti-inflammatory activity [9]. The methanol extract of Bougainvillea glabra was found to have significant thrombolytic [6] and antihyperlipidemic activities [10]. Gupta [11] found that hydroalcoholic extract from leaves of Bougainvillea glabra was active against some pathogenic microorganisms.

Hence the aim of present work was to standardize the whole plant of Bougainvillea glabra by the evaluation of various parameters, In addition, identification of various phytoconstituents was performed by preliminary phytochemical screening and thin layer chromatography studies.

\section{MATERIALS AND METHODS}

\section{Collection and authentication of plant material}

The whole plant of Bougainvillea glabra (Nyctaginaceae) was collected in the month of July from the botanical garden, Hanamkonda, Warangal district, Telangana, India. The plant material was taxonomically identified by Dr Vatsavaya S Raju, Professor, Plant Systematics Laboratory, Department of Botany, Kakatiya University, Warangal district, Telangana, India and a voucher specimen was deposited in the herbarium against accession number 4610 for future reference.

\section{Processing of plant material}

The collected Bougainvillea glabra whole plant was washed thoroughly under tap water. The plant was cut into small pieces and air-dried below shade (at room temperature) for one month to avoid direct loss of phytoconstituents from sunlight. Next, the shade dried 
materials were powdered using pulverizer and sieved up to 40 meshes. It was then made a uniform to a fine powder.

\section{Standardization}

\section{Loss on drying/Moisture content}

Place about 3.0 grams of Bougainvillea glabra plant powder, in an accurately weighed moisture disc. For estimation of loss on drying, it was dried at $100{ }^{\circ} \mathrm{C}$ for $4 \mathrm{~h}$ in an oven, then it was cooled in a desiccator for $30 \mathrm{~min}$, and it is weighed without delay. The loss of weight was calculated as the content in $\mathrm{mg}$ per $\mathrm{g}$ of air dried material.

\section{Determination of total ash}

Bougainvillea glabra plant powder (5 gm) was placed in a previously ignited $\left(300{ }^{\circ} \mathrm{C}\right.$ for $\left.45 \mathrm{~min}\right)$ and tarred crucible accurately weighed. The dried material was spread in a uniform layer in the container and the substance was ignited by gradually increasing the temperature to $400{ }^{\circ} \mathrm{C}$ for $4 \mathrm{~h}$ in a muffle furnace (Nabertherm) until it was white, indicating the absence of carbon. Then it was cooled in a desiccator and weighed. Total ash content was measured in mg per gram of air-dried material.

\section{Determination of water soluble ash}

Fifteen (15) $\mathrm{ml}$ of water was added to the crucible containing the total ash, covered with a watch glass and boiled gently for $15 \mathrm{~min}$. Insoluble matter was collected on an ash less filter paper. Then it was washed with hot water and ignited in a crucible for $10 \mathrm{~min}$ at a temperature of $400{ }^{\circ} \mathrm{C}$ in a muffle furnace. The residue was allowed to cool in a suitable desiccator for $20 \mathrm{~min}$ and then weighed without delay. The weight of the residue was subtracted in mg from the weight of total ash. Water-soluble ash content was calculated as mg per $g$ of air-dried material.

\section{Determination of acid-insoluble ash}

Fifteen (15) $\mathrm{ml}$ of hydrochloric acid $(60 \mathrm{~g} / \mathrm{l})$ total solid content (TS) was added to the crucible containing the total ash. It was covered with a watch-glass and then boiled gently for $15 \mathrm{~min}$. The watchglass was rinsed with a little amount of hot water and this liquid was added to the crucible. The insoluble matter was collected on an ash less filter-paper (Whatmann-41) and washed with hot water until the filtrate was neutral. The filter paper containing the insoluble matter was transferred to the original crucible, and then it was ignited by gradually increasing the heat to $450{ }^{\circ} \mathrm{C}$ for $2 \mathrm{~h}$ in a muffle furnace (Nabertherm) to constant weight. The residue was allowed to cool in a suitable desiccator for $20 \mathrm{~min}$ and then weighed without delay. Acid-insoluble ash content was calculated as mg per $\mathrm{g}$ of air dried material.

\section{Determination of sulfated ash}

A suitable crucible (silica) ignited at $450^{\circ} \mathrm{C}$ to $550^{\circ} \mathrm{C}$ for $25 \mathrm{~min}$ and the crucible was cooled in a desiccator (silica gel) and was weighed it accurately. One gram of the whole plant powder of the Bougainvillea glabra was placed in a previously ignited crucible, ignited gently at first until the substance was thoroughly white. The residue was ventilated and humidified with a small amount (usually $1 \mathrm{ml})$ of sulfuric acid $(1660 \mathrm{~g} / \mathrm{l})$. Total solid heated gently at a temperature as low as practicable until the sample was thoroughly charred. After cooling, the residue was moistened with a small amount (usually $2 \mathrm{ml}$ ) of sulfuric acid $(1660 \mathrm{~g} / \mathrm{l})$. Total solid content heated moderately till white fumes were no longer progressed and ignited at $600{ }^{\circ} \mathrm{C}+25^{\circ} \mathrm{C}$ until the residue was totally incinerated. Ensure that flames were not produced at any time during the procedure. The crucible was cooled in a desiccator (silica gel), weighed accurately. This was repeated until the sample reaches a constant weight and the percentage of the residue was calculated.

\section{Determination of $\mathrm{pH}$ range}

The $\mathrm{pH}$ of different formulations in 2\% w/v (2g: $100 \mathrm{ml}$ ) and 20\% $\mathrm{w} / \mathrm{v}(20 \mathrm{~g}: 100 \mathrm{ml}$ ) of water soluble portions of whole plant powder of Bougainvillea glabra were determined using standard simple glass electrode $\mathrm{pH}$ meter [12].

\section{Determination of hot water and ethanol-extractable matter}

Separately place about $2.0 \mathrm{~g}$ of whole plant powder of the Bougainvillea glabra, in an accurately weighed, glass stoppered conical flask. For estimation of hot water extractable matter, $50 \mathrm{ml}$ of distilled water was added to the flask and weighed to obtain the total weight including the flask. The contents were shaken well and allowed to stand for $45 \mathrm{~min}$. A reflux condenser was fixed to the flask and heated gently for 1 hour; chilled and weighed. The flask was readjusted to the original total weight with distilled water and it was shaken well and filtered rapidly through a dry filter.

Then $15 \mathrm{ml}$ of the filtrate was transferred to an accurately weighed, tarred flat-bottomed dish (Petri disc) and evaporated to dryness on a water-bath. Finally, it was dried at $100^{\circ} \mathrm{C}$ for $4 \mathrm{~h}$ in an oven, and it was cooled in a desiccator for 20 min and weighed without delay. Similar process was monitored using ethanol in its place of distilled water to govern extractable matter in ethanol. The extractable matter was calculated as the content in mg per gm of air-dried material.

\section{Extraction}

Powder of Bougainvillea glabra was individually extracted with chloroform, ethyl acetate and methanol by continuous soxhlet extraction method. The solvents were removed by rotary vacuum evaporator, the remaining mass of extracts were concentrated and dried. The extracts were stored in a desiccator for further studies.

\section{Phytochemical screening}

The phytochemical screening was carried out by standard procedures [13]. Different extracts of Bougainvillea glabra were subjected to preliminary phytochemical screening for the detection of various phytochemical constituents such as carbohydrates, proteins, amino acids, steroids, tannins, flavonoids, alkaloids and glycosides.

Several tests are as follows:

\section{A. Test for alkaloids}

Sample (chloroform, ethyl acetate and methanol extract) was evaporated, to the residue dilute hydrochloric acid was added. It was shaken well and filtered. With the extract, subsequent tests were carried out.

\section{- Dragendorff's test}

A small quantity of the sample was treated with the few drops of Dragendorff's reagent, the appearance of reddish brown precipitate indicated the presence of alkaloids

\section{Mayer's test}

Sample (2-3 ml) was treated with few drops of Mayer's reagent. The appearance of white precipitate indicated the presence of alkaloids.

\section{Hager's test}

Sample $(2-3 \mathrm{ml})$ was treated with Hager's reagent. The appearance of yellow precipitate indicated the presence of alkaloids.

\section{Wagner's test}

Sample (2-3 ml) was mixed with few drops of Wagner's reagent. Appearance of reddish brown precipitate indicated the presence of alkaloids.

\section{B. Test for proteins [14]}

\section{- Biuret test (General test)}

A test sample $(3 \mathrm{ml})$ was mixed with $4 \% \mathrm{NaOH}$ and few drops of $1 \%$ $\mathrm{CusO}_{4}$ solution were added. Violet or pink color not appeared.

\section{- Millon's test}

A test sample $(3 \mathrm{ml})$ was mixed with $5 \mathrm{ml}$ of million's reagent. The White precipitate is formed. On warming precipitate turn's brick red or the precipitate dissolves giving red coloured solution. 


\section{- Xanthoprotein test for proteins containing tyrosine or tryptophan}

Test solution ( $3 \mathrm{ml}$ ) was mixed with $1 \mathrm{ml}$ of conc sulphuric acid. White precipitate is formed. It was boiled then precipitate turned yellow. Ammonium hydroxide was added, finally precipitate turned orange.

\section{Tests for amino acids [14]}

\section{- Ninhydrin test (General test)}

Test sample $3 \mathrm{ml}$ and 3 drops of 5\% ninhydrin solution were heated in boiling water for $10 \mathrm{~min}$. The purple colour does not appear.

\section{Test for steroids [14]}

Sample $2 \mathrm{ml}$ was mixed with $2 \mathrm{ml}$ of conc Sulphuric acid, it was well shaken then chloroform layer appeared red and acid layer has shown greenish yellow fluorescence.

\section{- Liebermann-burchard reaction}

Sample (2 ml) was mixed with chloroform. 1-2 $\mathrm{ml}$ of acetic anhydride was added and 2 drops conc. Sulphuric acid was added from the sides of the tube. First red then blue and finally green colour appeared.

\section{- Liebermann's reaction}

Sample $(3 \mathrm{ml})$ was mixed with $3 \mathrm{ml}$ of acetic anhydride. It was first heated and then cooled, later few drops of conc. Sulphuric acid was added and blue colour appeared.

\section{E. Test for glycosides [14]}

Free content of the sugar extract was determined. The sample was hydrolyzed with mineral acid (dilute hydrochloric or dilute sulphuric acid). Again the total sugar content of the hydrolyzed extract was determined. Increase in the sugar content indicated the presence of glycoside in the extract.

$$
\text { Glycoside } \mathrm{HOH} \text { Aglycon (genin) + Glycon (sugar) }
$$

Tests for Cardiac Glycosides (Rimjhim Sheel et al., 2014)

\section{- Keller Killiani test}

- The sample was dissolved in $2 \mathrm{ml}$ chloroform. $\mathrm{H}_{2} \mathrm{SO}_{4}$ was added to form a layer and the colour at interphase is recorded. Brown ring at interphase is characteristic of deoxy sugars in cardenolides.

- In $2 \mathrm{ml}$ extract, GAA and 1 drop of $5 \%$ of $\mathrm{Fecl}_{3}$ and conc $\mathrm{H}_{2} \mathrm{SO}_{4}$ were added. Reddish brown colour will be seen at the intersection of two liquid layers, and top layer appears bluish green, confirming the presence of glycosides.

\section{Test for saponin glycosides [14]}

- Foam test: The drug sample or dry powder was shaken vigorously with water. The persistent foam was observed.

- Hemolytic test: drug sample or dry powder was added to one drop of blood placed on glass slide. Hemolytic zone was observed.

\section{F. Tests for flavonoids [14]}

- Shinoda test: Sample extract was treated with $5 \mathrm{ml}$ of $95 \%$ ethanol; few drops of conc. Hydrochloric acid and 0.5g of magnesium turnings were also added. The pink colour was observed. Addition of increasing amount of sodium hydroxide to the residue shown yellow colouration, which decolorizes after addition of acid indicates the presence of flavonoids.

\section{G. Tests for tannins [14]}

The sample was treated with $10 \%$ lead acetate solution; the appearance of white precipitate indicated the presence of tannins. When the extract was treated with aqueous bromine solution, the appearance of white precipitate indicated the presence of tannins.

\section{H. Tests for sterols [14]}

The sample was treated with $5 \%$ potassium hydroxide solution appearance of pink colour indicates the presence of sterols.

\section{Thin layer chromatography}

TLC plates were prepared by using silica Gel-GF 254 as an adsorbent $10 \mathrm{gm}$ silica gel-G was mixed with $20 \mathrm{ml}$ of distilled water (1:2) to make a slurry. The slurry was immediately poured into the plates. Plates were then allowed to dry for one hour and the layer was fixed by drying at $100{ }^{\circ} \mathrm{C}$ for $2 \mathrm{~h}$. using a micropipette, about $10 \mu \mathrm{l}$ of extracts were loaded gradually over the plate and air dried. Then the plates were developed in different solvent systems such as (chloroform: acetone: diethyl amine-5:3:2); (dioxane: ammonia 24\%-7:3); (benzene: ethyl acetate-85:15); (chloroform: methanol-8:2); (toluene: dioxin: acetic acid-78:14:5); (benzene: ethanol-8.5:1.5) and (chloroform: acetone: formic acid-64:12.3:3.2). The different solvent systems showed different $\mathrm{R}_{\mathrm{f}}$ value for the same plant extract. The chromatograms were observed under visible light and were photographed.

The $\mathrm{R}_{\mathrm{f}}$ value was achieved by means of the following formula.

$$
\mathrm{R}_{\mathrm{f}}=\frac{\text { Distance travelled by the solute }(\mathrm{cm})}{\text { Distance travelled by the solvent }(\mathrm{cm})}
$$

\section{RESULTS}

\section{Standardization}

Different physicochemical constants were determined three times and the average values were recorded. The plant extract has shown dissimilar values for several parameters. For loss on drying, the value for Bougainvillea glabra was found to be $8.1+0.24$ and the total ash value was $6.26 \pm 0.05$. The result for acid insoluble ash and sulfated ash was found to be $1.35 \pm 0.03$ and $1.10 \pm 0.07$, respectively. The $\mathrm{pH}$ value of crude drug indicates whether the drug will be absorbed in intestine or stomach. The $\mathrm{pH}$ of different formulations in 2\% w/v (2g: $100 \mathrm{ml})$ and 20\% w/v (20g: $100 \mathrm{ml})$ formulations of whole plant powder of Bougainvillea glabra were found to be $4.12 \pm 0.03$ and $2.92 \pm 0.05$ respectively. The extractive values for both water and ethanol were found to be $23.45 \pm 1.13$ and $12.32 \pm 0.41$. Water soluble ash value was found to be $1.34 \pm 0.04$. Results of extractive value determination show that Water soluble extractive value $23.45 \pm 1.13$ was more than the ethanol soluble extractive value $12.32 \pm 0.41$. The results were given in the table 1 .

\section{Determination of solvent extractive values}

The table 2 shows the extractive values of Bougainvillea glabra.

The air dried powder of Bougainvillea glabra was extracted with different solvent systems like chloroform, ethyl acetate and methanol. The percentage yields of different extracts were found to be $3.8 \% 4.2 \%$ and $4.8 \%$ for chloroform, ethyl acetate and methanol, respectively.

Table 1: Physicochemical parameters of Bougainvillea glabra

\begin{tabular}{ll}
\hline Parameters & Values \\
\hline Loss on drying & $8.15 \pm 0.24 \mathrm{~W} / \mathrm{W}$ \\
Total ash value & $6.26 \pm 0.05 \mathrm{~W} / \mathrm{W}$ \\
Water soluble ash & $1.34 \pm 0.04 \mathrm{~W} / \mathrm{W}$ \\
Acid insoluble ash & $1.35 \pm 0.03 \mathrm{~W} / \mathrm{W}$ \\
Sulfated ash value & $1.10 \pm 0.07 \mathrm{~W} / \mathrm{W}$ \\
pH of 2\% w/v formulation solution & $4.12 \pm 0.03$ \\
pH of 20\% w/v formulation solution & $2.92 \pm 0.05$ \\
Water soluble (hot) extractive value & $23.45 \pm 1.13 \mathrm{~W} / \mathrm{W}$ \\
Ethanol soluble (hot) extractive value & $12.32 \pm 0.41 \mathrm{~W} / \mathrm{W}$ \\
\hline
\end{tabular}


Table 2: Data showing the extractive value of Bougainvillea glabra

\begin{tabular}{llll}
\hline Plant name & Part used & \multicolumn{3}{l}{ \% Yields of extracts (\%w/w) } \\
\cline { 2 - 4 } & & CH Chloroform & Ethyl acetate \\
\hline Bougainvillea glabra & Whole plant & $3.8 \%$ & $4.2 \%$ \\
\hline
\end{tabular}

\section{Phytochemical screening}

Preliminary phytochemical screening of Bougainvillea glabra was carried out with three different extracts and the data was represented in table 3 . The preliminary phytochemical studies revealed the presence of alkaloids, steroids, glycosides and flavonoids in chloroform extract. Some phytoconstituents were observed in ethyl acetate extract viz., steroids, glycosides and flavonoids. Further, some phytoconstituents like alkaloids, steroids, glycosides, flavonoids and tannins were shown in methanol extract.

Table 3: Phytochemical constituents of Bougainvillea glabra plant extracts.

\begin{tabular}{|c|c|c|c|c|c|c|}
\hline S. No. & & Chemical test & Observation & Infere & & \\
\hline \multirow[t]{3}{*}{ A. } & 1 & For alkaloids & Reddish brown precipitate & $\mathrm{CHCl}_{3}$ & EtoAc & МeOH \\
\hline & & Dragendorff's test & White precipitate & & & \\
\hline & & Mayer's test & & ++ & -- & ++ \\
\hline \multirow[t]{4}{*}{ B. } & 2 & For Proteins & & -- & -- & -- \\
\hline & & Biuret test(General) & Violet/Pink color & & & \\
\hline & & Million's test & Red color precipitate & & & \\
\hline & & Xanthoprotein test & Orange color & & & \\
\hline \multirow[t]{2}{*}{ C. } & 3 & For Amino acids & & & & \\
\hline & & Ninhydrin test & Purple/Bluish color & -- & -- & -- \\
\hline \multirow[t]{4}{*}{ D. } & 4 & For Steroids & & ++ & ++ & ++ \\
\hline & & Salkowski reaction & Yellow Fluorescence & & & \\
\hline & & Lieberman-Burchard reaction & Green color & & & \\
\hline & & Liebermann's reaction & Blue color & & & \\
\hline \multirow[t]{2}{*}{ E. } & 5 & For Glycosides & & & & \\
\hline & & $\begin{array}{l}\text { Cardiac glycosides } \\
\text { (Keller-Killiani) Test }\end{array}$ & --- & ++ & ++ & ++ \\
\hline \multirow[t]{2}{*}{ F. } & 6 & For Flavonoids & & ++ & ++ & ++ \\
\hline & & Shinoda test & Pink color & & & \\
\hline \multirow[t]{3}{*}{ G. } & 7 & For Tannins & & -- & -- & ++ \\
\hline & & Test 1 & White Precipitate & & & \\
\hline & & Test 2 & White Precipitate & & & \\
\hline
\end{tabular}

\section{Thin layer chromatography}

\section{Chloroform extract}

The thin layer chromatography analysis of Bougainvillea glabra chloroform extract showed the presence of steroids with $\mathrm{R}_{\mathrm{f}}$ values of 0.66 and 0.34 in benzene: ethyl acetate (85:15) and chloroform: methanol (8:2) solvent systems correspondingly. Iodine vapours and UV-light were applied for the detection of steroids. Appearance of the yellow zone and intense fluorescence indicated the presence of steroids in chloroform extract.

\section{Ethyl acetate extract}

The thin layer chromatography analysis of ethyl acetate extract of Bougainvillea glabra showed the presence of flavonoids with $\mathrm{Rf}$ values of 0.66 and 0.75 in toluene: dioxin: acetic acid (78:14:5) chloroform: acetone: formic acid (64:12.3:3.2) solvent systems correspondingly. Iodine vapours and Natural products-poly ethylene glycol reagent (NP/PEG) were applied for the detection of flavonoids. Appearance of the orange yellow zone and intense fluorescence indicated the presence of flavonoids in ethyl acetate extract.

\section{Methanol extract}

It was observed that thin layer chromatography analysis of Bougainvillea glabra plant showed the presence of alkaloids in methanol extract. It was observed that the thin layer chromatography analysis of Bougainvillea glabra methanol extract showed the presence of alkaloids with $\mathrm{R}_{\mathrm{f}}$ values of 0.26 and 0.64 in [chloroform: acetone: diethyl amine (5:3:2)] and dioxane: ammonia 25\% (7:3) solvent systems respectively. Marquis reagent and Ninhydrin were applied for the detection of alkaloids. Appearance of violet fluorescence and gray colour indicated the presence of alkaloids in chloroform extract. $R_{f}$ values of solutes separated from the various extracts of Bougainvillea glabra was tabulated as table 4,5 and 6.

Table 4: Steroids: TLC studies for chloroform extract of Bougainvillea glabra

\begin{tabular}{|c|c|c|c|c|}
\hline Solvent system for chloroform extract of Bougainvillea glabra & Spraying reagent & Colour of spots & Rf value & Inference \\
\hline $\begin{array}{l}\text { Benzene: Ethyl acetate }(85: 15) \text { for Chloroform extract of Bougainvillea } \\
\text { glabra }\end{array}$ & Iodine vapours & Yellow zone & 0.66 & $\begin{array}{l}\text { Presence of } \\
\text { Steroids }\end{array}$ \\
\hline $\begin{array}{l}\text { Chloroform: Methanol(8:2) for Chloroform extract of Bougainvillea } \\
\text { glabra }\end{array}$ & UV-light & $\begin{array}{l}\text { Intense } \\
\text { fluorescence }\end{array}$ & 0.34 & $\begin{array}{l}\text { Presence of } \\
\text { Steroids }\end{array}$ \\
\hline
\end{tabular}

Table 5 Flavonoids: TLC studies for ethyl acetate extract of Bougainvillea glabra

\begin{tabular}{|c|c|c|c|c|}
\hline Solvent system for ethyl acetate extract Bougainvillea glabra & Spraying reagent & Colour of spots & Rf value & Inference \\
\hline $\begin{array}{l}\text { Toluene: dioxin: acetic acid (78:14:5) for ethyl acetate extract of } \\
\text { Bougainvillea glabra }\end{array}$ & Iodine vapour & Orange-yellow & 0.66 & $\begin{array}{l}\text { Presence of } \\
\text { Flavonoids }\end{array}$ \\
\hline $\begin{array}{l}\text { Chloroform: acetone: formic acid (64:12.3:3.2) for ethyl acetate } \\
\text { extract of Bougainvillea glabra }\end{array}$ & $\begin{array}{l}\text { Natural products-poly } \\
\text { ethylene glycol } \\
\text { reagent }\end{array}$ & $\begin{array}{l}\text { Intense } \\
\text { fluorescence } \\
\text { colour }\end{array}$ & 0.75 & $\begin{array}{l}\text { Presence of } \\
\text { Flavonoids }\end{array}$ \\
\hline
\end{tabular}


Table 6 Alkaloids: TLC studies for methanol extract of Bougainvillea glabra

\begin{tabular}{|c|c|c|c|c|}
\hline Solvent system for methanol extract Bougainvillea glabra & $\begin{array}{l}\text { Spraying } \\
\text { reagent }\end{array}$ & $\begin{array}{l}\text { Colour of } \\
\text { spots }\end{array}$ & $\begin{array}{l}\text { Rf } \\
\text { value }\end{array}$ & Inference \\
\hline $\begin{array}{l}\text { Chloroform: acetone: diethyl amine }(5: 3: 2) \text { for methanol extract of } \\
\text { Bougainvillea glabra }\end{array}$ & Marquis reagent & $\begin{array}{l}\text { Violet } \\
\text { fluorescence }\end{array}$ & 0.26 & $\begin{array}{l}\text { Presence of } \\
\text { Alkaloids }\end{array}$ \\
\hline Dioxane: ammonia 24\% (7:3) for methanol extract of Bougainvillea glabra & Ninhydrin & Grey colour & 0.64 & $\begin{array}{l}\text { Presence of } \\
\text { Alkaloids }\end{array}$ \\
\hline
\end{tabular}

\section{DISCUSSION}

The physicochemical parameters of whole plant powder of Bougainvillea glabra were estimated based on the methods recommended by World Health Organization (WHO). Standardization is useful for determining crude drugs and it gives an idea about the nature of the chemical constituents present [1]. Standardization can show a vital role in the estimation of herbal drugs and can also become a significant quality control method as well as for suitable stability testing of the product. India can emerge as the major country and play the lead role in the production of standardized, therapeutically effective ayurvedic formulation. India needs to explore the medicinally important plants. Standardization of herbal formulations is essential in order to evaluate the quality of drugs, based on the concentration of their active principles. The traditional approach towards standardization is insufficient for current herbal market and hence there is a need for more advanced techniques for standardization. The plant extract of Bougainvillea glabra has shown different values for several parameters. For loss on drying, it was dried at $100{ }^{\circ} \mathrm{C}$ for $4 \mathrm{~h}$ in an oven and then cooled, loss on drying was found to be $8.1+0.24$. The less value of moisture content of drugs could prevent content bacterial, fungal or yeast growth through storage [15]. The total ash value was 06.26 \pm 0.05 . Ash values used to find out quality, authenticity and purity of unsophisticated drug and also these values are important quantitative standards [16]. The $\mathrm{pH}$ of different formulations in $2 \%$ w/v (2g: $100 \mathrm{ml}$ ) and 20\% w/v (20g: $100 \mathrm{ml})$ of water soluble portions of whole plant powder of Bougainvillea glabra were found to be nearly similar. It works on the principle that drug in the opposite $\mathrm{pH}$ are unionized and absorbed rapidly from the stomach/intestine accordingly. The extractive values for both water and ethanol were found to be $23.45 \pm 1.13$ and $12.32 \pm 0.41$. The extractive values are valuable to estimate the chemical constituents present in the crude drug and furthermore assist in the evaluation of definite constituents soluble in a particular solvent [17].

Phytoconstituents play an important role in the field of new drugs research and development because of their low toxicity, easy availability and cost effective. The most important of these bioactive constituents of plants are alkaloids, tannins, flavonoids and phenolic compounds. Numerous original medicinal plants are used as flavors and nutrition plants. They are also sometimes added to food for medicinal purposes for pregnant and nursing mothers More than 2000 phytochemicals have been identified from plants. Flavonoids are an important group of polyphenols widely distributed among the plant flora. Structurally, they are made of more than one benzene ring in its structure (a range of C15 aromatic compounds) and numerous reports support their use as antioxidants or free radical scavengers.

As shown in the table 3 preliminary phytochemical screening of various extracts of Bougainvillea glabra has shown the presence of various phytoconstituents like the presence of alkaloids, steroids, glycosides and flavonoids in chloroform extract. Steroids, glycosides and flavonoids observed in ethyl acetate extract. Some phytoconstituents like alkaloids, steroids, glycosides, flavonoids and tannins were shown in methanol extract. The presence of various phytoconstituents in the plant Bougainvillea glabra may be responsible for the different pharmacological activities of the plant.

Thin-layer chromatography (TLC) is a separation technique used to distinct non-volatile mixtures. A large number of solvent systems were tried to achieve a good resolution. TLC profiling of all the extracts denotes an imposing result that guiding towards the incidence of a number of phytochemicals. Various phytochemicals gave different $R_{f}$ values in the different solvent system. This dissimilarity in $\mathrm{R}_{\mathrm{f}}$ values of the phytochemicals affords a very vital clue in accepting of their polarity and also helps in selection of a suitable solvent system for separation of pure compounds by column chromatography. Mixture of solvents with variable polarity in different ratio can be used for separation of the pure compound from plant extract. The selectivity of a correct solvent system for specific plant extracts can only be attained by examining the $R_{f}$ values of compounds in the diverse solvent system. Different $R_{f}$ values of the compound also reflect an idea about their polarity.

As seen in the table all the extracts were subjected to thin layer chromatography by using different solvent systems. The TLC profiling of all the extracts in chloroform: acetone: diethyl amine (5:3:2), dioxane: ammonia 25\% (9:1), benzene: ethyl acetate (85:15), chloroform: Methanol (8:2), toluene: dioxin: acetic acid (78:14:5), chloroform: acetone: formic acid (64:12.3:3.2) solvent systems confirms the presence of diverse potent bio molecules in these plants. TLC investigation deliver an impression about the polarity of numerous chemical constituents, in a way such that compound displaying high $R_{f}$ value in the less polar solvent system have low polarity and with less $R_{f}$ value have high polarity. These potent biomolecules can be further used for development of the different drug in future.

\section{CONCLUSION}

The present work was taken up in the view to completely standardize the herb in accordance to parameters of World Health Organization (WHO) Guidelines and standard laboratory procedures. Extraction, standardization and phytochemical screening were done to evaluate the qualitative and quantitative parameters of Bougainvillea glabra. The study of the whole plant of Bougainvillea glabra was thoroughly investigated for their organoleptic characters; physicochemical characters and major active constituents to analyze their superiority, protection and standardization for their safe use. The values of each parameter were found to be within the prescribed limits as per WHO. The phytochemical and TLC studies have shown that the plant extracts of Bougainvillea glabra possess flavonoids, terpenoids and steroids were present in chloroform, ethyl acetate and methanol extracts. The results of the study also provide an evidence to conclude that the plant Bougainvillea glabra leaves can be used to treat various diseases like cancer and heart-related diseases etc. The generated information of the present study will provide data which is helpful in the correct identification and authentication of this medicinal plant and may help in preventing its adulteration.

\section{ACKNOWLEDGEMENT}

The authors are thankful to the management of GITAM University, Visakhapatnam, Andhra Pradesh, India and the management of Chaitanya College of Pharmacy Education and Research, Kishanpura, Hanamkonda, Warangal, Telangana, India for providing the necessary facilities to carry out the research work.

\section{CONFLICT OF INTERESTS}

Declare none

\section{REFERENCES}

1. Dixit VK, Yadav NP. Recent approaches in herbal drug standardization. Integr Biol 2008;2:195-203.

2. Patel PM, Patel NM, Goyal RK. Quality control of herbal products. Indian Pharm 2006;5:26-30.

3. Istieake A, Sabbir Ahmed O, Ahmed Abrar M, Al-Mamun, Tabibul Islam, Protiva Rani D, et al. Plant remedies of a Unani 
medicinal practitioner in Bhola district, Bangladesh. World J Pharm Pharm Sci 2015;4:186-98.

4. Simmonds MSJ, Howes MJR. Edited by Soumyanath A. Traditional Medicines for Modern Times: Antidiabetic Plants. Taylor and Francis Group, UK; 2006. p. 205-9.

5. Aguilar A, Camacho JR, Chino S, Jacques P, Lopez ME. Medicinal plants from the herbarium of Mexican Institute for social security (IMSS). Rev Med Inst Mex Seguro Soc 1994;1:5-15.

6. Elumalai A, Chinna Eswariah M, Vidhyulatha Chowdary $\mathrm{CH}$, Ranjith K, Anusha M, Naresh K. Screening of thrombolytic activity of Bougainvillea glabra leaves extract by in vitro. Asian J Res Pharm Sci 2012;2:134-6.

7. Perales YJ, Leysa M. Phytochemical screening and antibacterial activity of Bougainvillea glabra plant extract as potential sources of antibacterial and resistance-modifying agents. Int Con Life Sci Eng 2012;45:121-5.

8. Grace I, Adebayo, Oluwakemi T, Alabi, Bamidele V, Owoyele, et al. Anti-diabetic properties of the aqueous leaf extract of Bougainvillea glabra (Glory of the Garden) on alloxan-induced diabetic rats. Rec Nat Prod 2009;3:187-92.

9. Giri SN, Biswas AK, Saha BP, Pal SP, Pal M. Studies of the antiinflammatory action of Bougainvillea glabra leaves. Indian J Pharm Sci 1988;50:42-4.

10. Brajesh G, Srivastava NM, Savita Srivastava. Antihyperlipidemic effect of Bougainvillea glabra leaves in triton wr-1339 induced hyperlipidemic rats. Scholar Res Lib 2015;7:187-90.
11. Gupta V, George M, Joseph L, Singhal M, Singh HP. Evaluation of antibacterial activity of Bougainvillea glabra 'snow white' and Bougainvillea glabra 'choisy'. J Chem Pharm Res 2009;1:233-7.

12. Neeraj C, Bhupinder SS. An overview of advances in the standardization of herbal drugs. J Pharm Educ Res 2011;2:55-70.

13. Kokate CK, Purohit AP, Gokhale SB. Pharmacognosy $4^{\text {th }}$ edition. Nirali Prakashan, Pune; 1998. p. 122-8.

14. Khandelwal KR. Practical pharmacognosy: technique and experiments. 8th edition. Nirali Prakashan, Pune; 2000. p. 149-53.

15. Pandey MK, Singh GN, Rajeev KS, Sneh L. Standardization of Yakrit Plihantak Churna. An ayurvedic poly herbal formulation. Int J Pharm Sci Res 2012;3:171-6.

16. Paramjyothi S, Syed KM. Preliminary pharmacognostical and phytochemical evaluation of Portulaca quadrifida Linn". Int J Pharm Tech Res 2010;2:1699-702.

17. Shweta J, Chanderachud S, Pankaj K, Atul J, Ankur V. Pharmacognostic and phyto chemical investigations of the leaves of Zizyphus xylopyrus (Retz) Willd. Int J Pharm Pharm Sci 2011;3:122-5.

\section{How to cite this article}

- $\quad$ Rakam Gopi Krishna, Raja S. Standardization and phytochemical screening of Bougainvillea glabra. Int J Curr Pharm Res 2017;9(5):75-80. 